\title{
Transmission Line Fault Detection, Classification and Location using Wavelet Transform
}

\author{
P. Balakrishnan, K. Sathiyasekar
}

\begin{abstract}
This paper present a new algorithm for fault detection, classification and location of overhead transmission line using Wavelet Transform (WT) based Discrete Wavelet Transform (DWT) is proposed. The different system faults such as $L G, L L G$ and $L L L G$ in transmission line should be detect, classify and locate rapidly. The proposed method is based on the voltage and current signal information from the power model in $M A T L A B$ to generate the transient voltage and current signal in both time and frequency domain. DWT using “db6" as a mother wavelet is used to capture transient current signals and extract the high frequency detail coefficient for detecting and classifying the fault disturbance. The classification process is based on ground threshold value. The location of faults is carried out by obtaining the fault information from source terminal end to remote terminal end along with the total transmission line length. The proposed method is tested on the MATLAB/SIMULINK environment with the Simulink model. In simulation process the proposed algorithm achieved the fault detection, classification and locate all eleven types of possible fault in transmission line and the result are compared with the AR and MED method.
\end{abstract}

Index Terms - Wavelet transform, Discrete Wavelet Transform, fault detection, classification and location, Transmission line.

\section{INTRODUCTION}

The power system is mainly consisting of three parts generation, transmission and distribution. The transmission line is a very important because it processes the power supply from generating station into distribution and it provides the power supply to the customer continuously. In this transmission process the faults are happened due to lightning, weather and insulation failure etc. so that the protection of transmission line is necessary to clear such faults and quickly restore the power supply as soon as possible and it is very essential to satisfies the customer. The distance estimation of transmission line fault is used to identify the correct location of fault and easily to clear the fault quickly. In past several techniques are applied to clear the fault in transmission line, such techniques are FFT, impedance based numerical method, traveling wave method ANN. In FFT it used to extract the fundamental frequency component and it do not perform time localization. The ANN method is not suitable for detection of fault in transmission line with different phases [5]. Section II

Revised Manuscript Received on 14 August, 2019.

P.Balakrishnan, Professor/EEE, Malla Reddy Engineering College for Women Secundrabad, Email : bala4k@yahoo.com

K.Sathiyasekar, Professor/EEE, SA Engineering College Chennai Email: ksathiyasekar@gmail.com discusses the literature survey and it deals for protection of transmission line with different types of fault with its location is discussed briefly. In section III represent the existing method based on wavelet transform is discussed. The next section is described the proposed system logic. The proposed algorithm is based on DWT used to detect and classify all eleven types (Table 1) of fault and fault location also discussed. In section $\mathrm{V}$ the simulation process and the proposed system results are illustrated. In section VI the result is compared with the AR and MED technique. The last section is illustrated the conclusion and future work of the proposed system.

In this paper the transmission line fault detection, classification and location is proposed using wavelet transform based Discrete Wavelet Transform (DWT). The DWT is used to reconstruct the original signal and extract the high frequency detail. The high frequency detail current value is used to detect the fault correctly in three phase transmission line and the classification algorithm is based on eleven types of fault (LG, LL, LLG, LLL and LLLG). The location algorithm is based on local fault information from the source terminal end to remote terminal end. The simulation result for the proposed algorithm is used to detect, classify and locate the transmission line fault with good accuracy and fast operation and it compared with the AR and MED technique.

\section{LITERATURE SURVAY}

A Detailed literature survey is based on the transmission line protection using WT, it has to detect, classify and estimate the fault location during disturbance of fault in power system. The detection of fault location and distance estimation in transmission line using wavelet transform is proposed [1] and [2]. The DWT is used to detect the faulted current signal and to extract the high frequency detail coefficients. The protection of transmission line using DWT is proposed in [4] and [15]. The MATLAB/SIMULINK environment is used to test the proposed method and obtain the various fault condition along with its location. The result is obtained from the four types of wavelet family and the ' $\mathrm{db} 5$ ' is the most effective family that can detect the fault along with it location [2].

The traveling wave based fault location algorithm for combined transmission line without using line parameter is proposed [3]. The algorithm for fault clearing at high frequency transients is used to generate the fault transient and it no need for line parameters. The of simulation result shows that the proposed 
method is insensitive for fault type, inception angle, fault resistance and fault location. The accuracy of the proposed method is does not change with climate, humidity and aging, the overall location error is below $0.3 \%$.

Continuous wavelet transform based transmission line fault classification and location is proposed [6], [7] and [14]. In CWT the model current wave form are decomposed and extract the high frequency information in time domain. CWT is continuous for shifting operation and it operate maximum scale to perform analysis function.

Artificial Neural Network (ANN) is used for pattern recognition, classification and generalization [5], it has great powerful for fault classification and location with high accuracy compared with other conventional method. In $[5,8$, $10,12,17$, and 18], the combination of wavelet transform and ANN is used to detect, classify and locate the transmission line fault correctly along with its location. The WT is used to detect the fault from the three phase line correctly with the model current signals to extract the high frequency detail coefficients and ANN is used to classify and locate the fault in overhead transmission line with high accuracy. The ANN is does not used to detect the fault from the different phase line correctly [5]. Fault analysis of transmission line using wavelet theory is prposed [9 and 13], in [10] the analysis method is based harr and biorthognal wavelet. The wavelet method is test LL, LLG, LLL and LLLG faults in a simulation process. From this result the biorthognal is suitable than haar wavelet transform. The traveling wave based wavelet theory is to analysis the phase fault [14]. The result of faulted phase selection is insensitive for fault location, inception angle and resistance. Transmission line fault location using FFT and WT in power system [11], the DFT and WT is to analysis the non-stationary signal with time domain. The FFT and WT are extracting the information for the disturbance signal to detect and classify the fault from the power system.

DWT and GA based fault classification process is proposed in [16] the combination of GA and DWT is to identify the healthy and faulty condition for the given three phase current. The 'db1' as a mother wavelet to extract the high frequency detail. The result of classification accuracy is $99 \%$.

\section{EXISTING SYSTEM}

The existing system is based on the WT used to detect and classifying all possible fault in a transmission line along with its fault location. Among the various wavelet transform technique is proposed in literature. In wavelet transform the faulted three phase signals are generated from the model power system and this signals are decomposed with the filter bank and it extract the high frequency detail current value for detection of fault in a transmission line. In this existing method the four types of mother wavelet in wavelet family are used to extract the high frequency detail coefficient. The most commonly used mother wavelet is Daubechies ( $d b)$. The ' $\mathrm{db} 5$ ' is used in most of the existing method to detect and classify the fault from the disturbance of fault signal. The existing system is required multilevel wavelet decomposition which is employed with multilevel filtering by complex computation and it require long term calculation process to achieve protection of transmission line fault detection, classification and location.

\section{PROPOSED SYSTEM LOGIC}

The proposed logic is consists of three methods (i) Fault detection, (ii) Fault classification and (iii) Fault location. The voltage and current signals are generate from power system these signals are processing and extracting the information during the disturbance of fault. The proposed algorithm is depends on discrete wavelet transform which is used to extracting the information during the various fault condition.

\section{A. Fault Detection Process}

In general the power system consists of lots of disturbance during the fault or non-fault condition so the protection scheme is consider for clearing these disturbance. In detection process when the disturbance of fault is detect on the transmission line. The three phase current signals fed through the wavelet decomposition filter, it's used to reconstruct the original signal and extract the high frequency detail coefficients. If the first difference of high frequency detail coefficient value is exceed the threshold value the following logic is represent the detection of fault on transmission line.

$$
D(n)= \begin{cases}1 & |H F(n)-H F(n-1)|>T h \\ 0 & \text { no }\end{cases}
$$

The above logic is tested on three phase $(\mathrm{R}, \mathrm{Y}, \mathrm{B})$ line for every fault disturbance. In eq. 1 the logic 1 is represent the presence of fault and the logic 0 is represent absence of fault. Here the threshold (Th) value is fixed on the maximum range of the input current and voltage value. Thispaper considering a maximum input range is $10 \mathrm{v}$ and a sampling frequency of $2 \mathrm{kHz}$ and "db6" as a mother wavelet. The following fig 1 is shown the block diagram of detection of fault on proposed system logic.

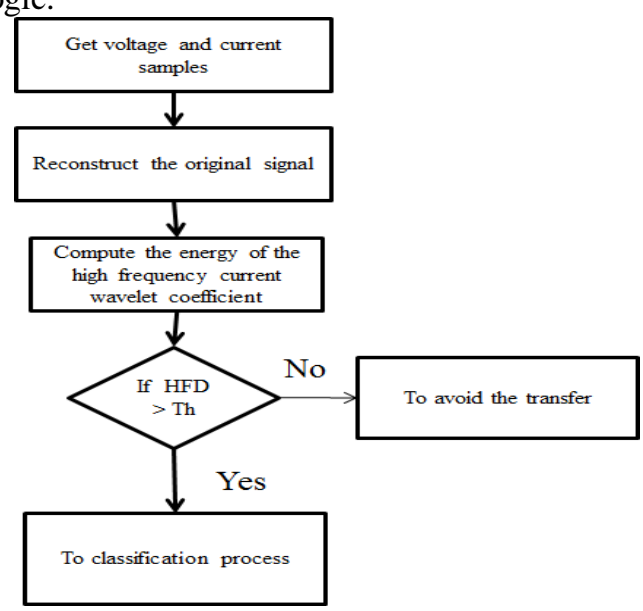

Fig.1. Fault Detection Diagram

\section{B. Fault Classification Process}

In this paper the proposed algorithm is based on that two separate logic, if the ground is present or not. This logic is necessary for the characteristics of presence of ground is different from compared to the absence of ground and it consider for separately. This paper the proposed classification algorithm is classifying all eleven types of fault on the transmission line these faults are illustrated as following table. 
TABLE.1. ELEVEN TYPES OF FAULT IN TL

\begin{tabular}{|c|c|c|}
\hline S.NO & FAULT PHASE & TYPES OF FAULT \\
\hline 1 & Phase A-Ground & \multirow{3}{*}{$\begin{array}{l}\text { Single phase fault } \\
\text { (LG) }\end{array}$} \\
\hline 2 & Phase B - Ground & \\
\hline 3 & Phase $\mathrm{C}-$ Ground & \\
\hline 4 & PhaseA - Phase B & \multirow{3}{*}{$\begin{array}{l}\text { Double phase fault } \\
\text { (LL) }\end{array}$} \\
\hline 5 & Phase A - Phase C & \\
\hline 6 & Phase B - Phase C & \\
\hline 7 & $\begin{array}{l}\text { Phase A - Phase B - } \\
\text { Ground }\end{array}$ & \multirow{3}{*}{$\begin{array}{l}\text { Double phase to } \\
\text { Ground fault (LLG) }\end{array}$} \\
\hline 8 & $\begin{array}{l}\text { Phase A - Phase C - } \\
\text { Ground }\end{array}$ & \\
\hline 9 & $\begin{array}{l}\text { Phase B - Phase C - } \\
\text { Ground }\end{array}$ & \\
\hline 10 & $\begin{array}{l}\text { Phase A - Phase B - } \\
\text { Phase C }\end{array}$ & $\begin{array}{l}\text { Three phase fault } \\
\text { (LLL) }\end{array}$ \\
\hline 11 & $\begin{array}{l}\text { Phase A - Phase B - } \\
\text { Phase C - Ground }\end{array}$ & $\begin{array}{c}\text { Three phase to } \\
\text { Ground fault (LLLG) }\end{array}$ \\
\hline
\end{tabular}

The effect of coupling on mutually coupled three phase transmission line is nullified. This achieved for a simple model transformation called karrenbaur transformation and it consists of summer/subtractor only. This transformation matrix is denoted by $\mathrm{T}$ and it shown follows.

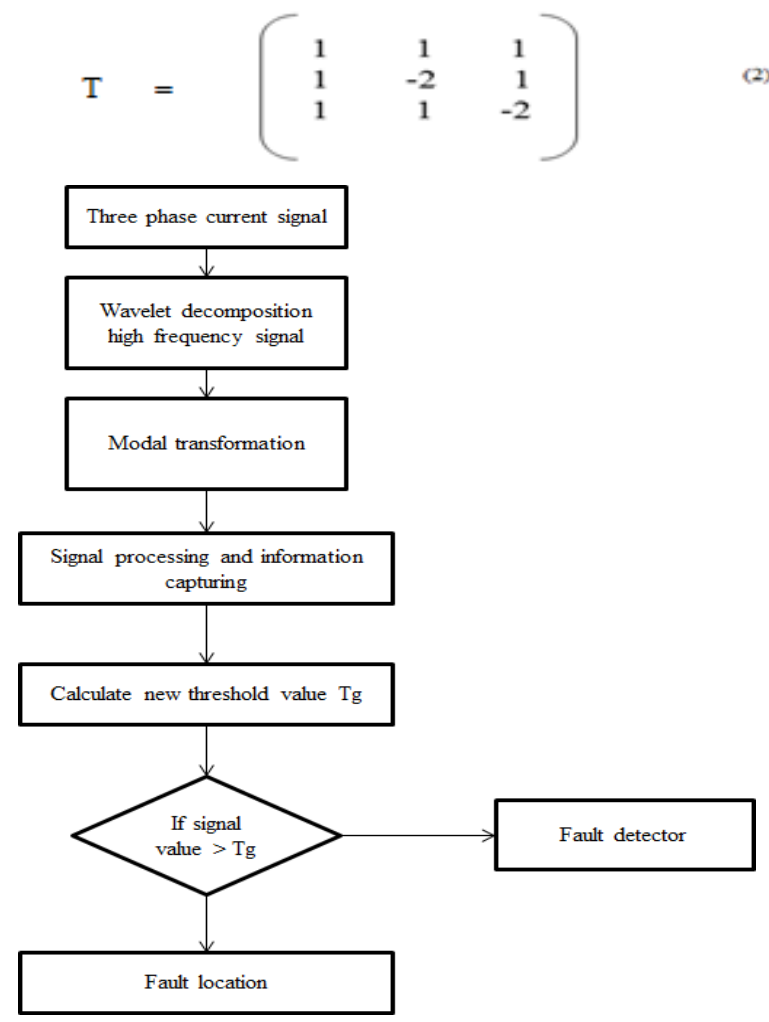

Fig.2. Fault Classification Diagram

In this proposed algorithm is consider as the phase B is reference after the transformation with the matrix $\mathrm{T}$ the signals $\mathrm{B} 0, \mathrm{~B} 1$ and $\mathrm{B} 2$ are getting from the following equation.

$$
\left[\begin{array}{l}
\text { Bo } \\
\text { B1 } \\
\text { B2 }
\end{array}\right]=\text { T } \times\left(\begin{array}{l}
\mathrm{HFR} \\
\mathrm{HFY} \\
\mathrm{HFB}
\end{array}\right]
$$

Similarly each phase R and Y can be obtain R0, R1, R2, $\mathrm{Y} 0, \mathrm{Y} 1$ and $\mathrm{Y} 2$ from that result it can represent as $\mathrm{R} 0=\mathrm{Y} 0=$ $\mathrm{B} 0, \mathrm{R} 1=\mathrm{B} 2, \mathrm{Y} 1=\mathrm{R} 2, \mathrm{~B} 1=\mathrm{Y} 2$. The faulted phase information can achieved from these four signals B0, R1, Y1, $\mathrm{B} 1$. When the high frequency detail coefficient is obtained from the detected signal during the fault disturbance these four signals are squared and cumulatively added to get the fault information of three phase line and ground fault.

$$
\begin{aligned}
& \text { Rinfo }=\sum \mathrm{B}_{1}{ }^{2} \\
& \text { Yinfo }=\sum \mathrm{R}_{1}^{2} \\
& \text { Binfo }=\sum \mathrm{Y}_{1}^{2} \\
& \text { Ginfo }=\sum \mathrm{R}_{0}{ }^{2}
\end{aligned}
$$

From that eq. 4 the information is captured and it ensures the fault disturbance is present in the three phase line and it essential to calculate the short span of time. Afterthe short time the captured information signal can be represent the value as Rv, Yv, Bv and Gv. From these values it can classify all possible faults correctly. The characteristics of presence of ground is different for absence of ground fault this paper the proposed algorithm when the ground is present the Gv value will not be zero for this characteristic a new set of discriminate signal value is achived and it denoted as $\mathrm{Rd}, \mathrm{Yd}$ and Bd. It can be obtained to multiply with the three phase R, $\mathrm{Y}$ and $\mathrm{B}$. The new threshold value is calculated as

$$
\mathrm{Tg}=\frac{\mathrm{Rd}, \mathrm{Yd}, \mathrm{Bd}}{3}
$$

If the ground is not present the Gv value will not be zero. From the eq. when the phase value is exceed the threshold level Tg that phase is consider for fault is present and it's a faulty line.

\section{Fault Location Process}

The fault location and distance estimation is essential in power system and it to clear the fault and restore the power quickly as soon as possible. When the transmission line fault disturbance is detected and classified the transmission line fault location process is performed. In this algorithm when the three phase current signals are decomposed the peak magnitude of current is to provide the information to the fault locator at the end of half cycle.

In this paper faulted phase signal is selected from the classifier output and to extract the information about local fault (IFLSE) from the source terminal end and information about local fault (IFLRE) from the remote terminal end. TL is denoted as the total length of the transmission line. In the following equation is to calculate actual distance of fault from the overhead transmission line when the fault disturbance is present.

$$
\mathrm{FL}=\frac{\text { IFLRE }_{\mathrm{T}} \mathrm{TL}}{\mathrm{IFLSE}_{\mathrm{S}}+\mathrm{IFL}_{\mathrm{RE}}}
$$




\section{SIMULATION AND RESULT ANALYSIS}

The simulation work for the proposed logic is tested on MATLAB/SIMULINK environment. The proposed system logic was based on wavelet transform and the eleven types of fault LG (A-G, B-G, C-G), LL (A-B, A-C, B-C), LLG (A-B-G, A-C-G, B-C-G), LLL/LLLG (Three phase fault/Three phase to ground fault) are created using the power system model in SIMULINK environment and these faults are tested using the generated waveforms in the proposed model. These waveforms were imported toMATLAB/ SIMULINK environment and given as input to the algorithm developed to detect and classify the fault with its location.

\section{A. Test System Model}

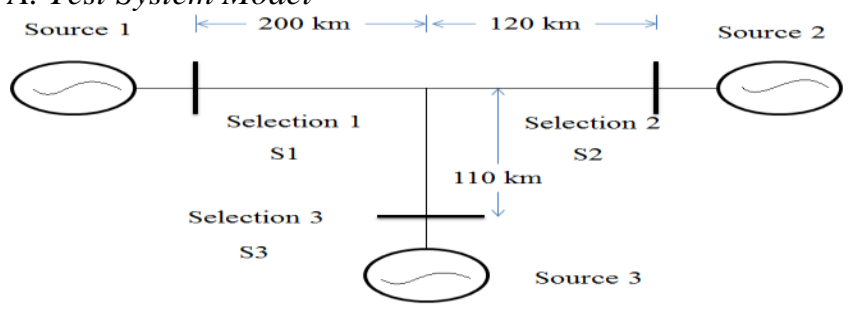

Fig.3. One Line Diagram of Model Test System

The performances studies in this paper are based on the $220 \mathrm{Kv}$ power system model it shown in Fig 4. The proposed system logic is tested and the various faults are generated using this test system model. It consist of three sources and it composed of $220 \mathrm{kv}$ transmission circuit with the selection lengths $200 \mathrm{~km}$ (section 1), $120 \mathrm{~km}$ (section 2) and $110 \mathrm{~km}$ (section 3), connected to sources at each end. Short circuit capacity of the equivalent thevenin sources on each sides of the line is considered to be $1.25 \mathrm{GVA}$ and $\mathrm{X} / \mathrm{R}$ ratio is 10 .

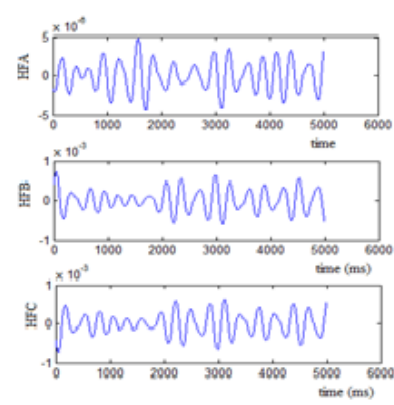

(a)

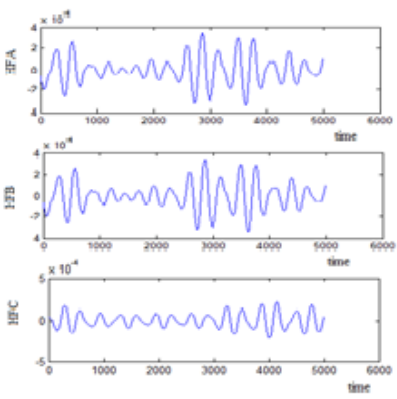

(b)
Fig 4. High Frequency Details for (a)BG Fault (b) BC fault With Respect To Bus 1

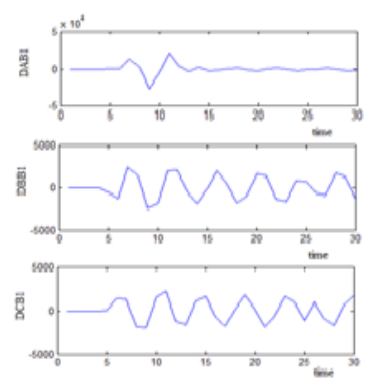

(a)

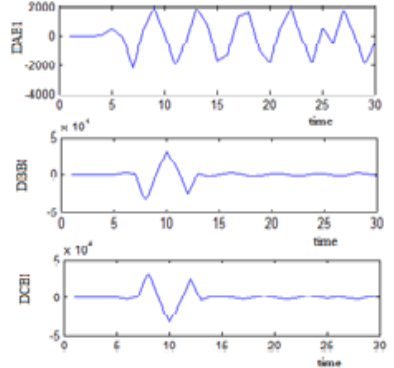

(b)
Fig 5. Fault detection for (a) BG Fault (b) BC Fault WithRespect To Bus 1
TABLE.2. SIMULINK MODEL PARAMETER VALUE

\begin{tabular}{|c|l|}
\hline Positive sequence resistance R1, $\Omega / \mathrm{KM}$ & 0.01809 \\
\hline Zero sequence resistance R0, $\Omega / \mathrm{KM}$ & 0.2188 \\
\hline Positive sequence inductance L1, H/KM & 0.00092974 \\
\hline Zero sequence inductance L0, H/KM & 0.0032829 \\
\hline $\begin{array}{c}\text { Positive sequence capacitance C1, } \\
\text { F/KM }\end{array}$ & $1.2571 \mathrm{e}-008$ \\
\hline Zero sequence capacitance C0, F/KM & $7.8555 \mathrm{e}-009$ \\
\hline
\end{tabular}

\section{B. Phase and Ground Fault}

The fault detection, classification and location process of the simulation test system is discussed for the proposed logic. In this discussion phase fault (YB) and ground fault (RG) is consider with respect to bus 1 . The fig. 5 shows fault detects signals for phase fault (YB) and ground fault (RG). The detection process is based on the eq. 1 which is used to detect the high frequency detail signal is exceed the threshold value. The fig.4 shows high frequency detail coefficient of phase fault (BY) and ground fault (RG). After detection of fault in the three phase line (R, Y and B) if Rv, Yv and Bv exceed the threshold value $\mathrm{Th}$ it can be set with different values for each three phase. If ground is present the $\mathrm{Gv}$ will be non-zero and the Gv value exceed the threshold level Tl. When ground is present the fault signal calculated using the eq.5 the faulted phase is detected using $\mathrm{Rv}, \mathrm{Yv}$ and $\mathrm{Bv}$ which is exceed the adaptive threshold value $\mathrm{Tg}$. The fault location is calculated using the eq. 6 for each faulted phase it takes the fault information for source terminal end and remote terminal end with the total length of the transmission line.

TABLE.3.DISCRIMINATION SIGNAL AND THRESHOLD VALUE

\begin{tabular}{|c|c|c|c|}
\hline \multicolumn{2}{|c|}{ Phase fault } & \multicolumn{2}{|c|}{ Ground fault } \\
\hline $\begin{array}{ll} & \mathrm{A} \\
\mathrm{V} & \\
\end{array}$ & 2.5093 & $\mathrm{~d}^{\mathrm{A}}$ & $\begin{array}{c}4.4370 \mathrm{e}+1 \\
1\end{array}$ \\
\hline $\begin{array}{r}\mathrm{B} \\
\mathrm{v} \\
\end{array}$ & 1.1198 & $\mathrm{Bd}$ & $\begin{array}{c}8.3617 \mathrm{e}+1 \\
2 \\
\end{array}$ \\
\hline $\begin{array}{ll} & \mathrm{C} \\
\mathrm{v} & \\
\end{array}$ & 1.3896 & $\mathrm{Cd}$ & $\begin{array}{c}3.7206 \mathrm{e}+1 \\
1\end{array}$ \\
\hline $\begin{array}{c}\text { TpA;TpB } \\
; \mathrm{TpC} \\
\end{array}$ & $\begin{array}{c}2.47 ; 1.1 ; 1 \\
45\end{array}$ & $\mathrm{Tc}$ & $\begin{array}{c}2.7872 \mathrm{e}+1 \\
2 \\
\end{array}$ \\
\hline $\mathrm{v}^{\mathrm{G}}$ & 1.7590 & $\mathrm{v}$ & $\begin{array}{c}2.0703 \mathrm{e}+0 \\
9\end{array}$ \\
\hline $\begin{array}{ll} & \mathrm{T} \\
\mathrm{g} & \\
\end{array}$ & 2 & $\mathrm{Tg}$ & 2 \\
\hline $\begin{array}{c}\mathrm{FC}[\mathrm{A} ; \mathrm{B} ; \\
\mathrm{C} ; \mathrm{G}]\end{array}$ & {$[1 ; 1 ; 0 ; 0]$} & $\begin{array}{c}\mathrm{FC}[\mathrm{A} ; \mathrm{B} ; \mathrm{C} ; \\
\mathrm{G}]\end{array}$ & {$[0 ; 1 ; 01]$} \\
\hline
\end{tabular}

\section{RESULT COMPARISION}

This paper the proposed algorithm for transmission line fault detection, fault classification and fault location using WT based DWT is compared to the Auto Regressive (AR) and Minimum Entropy Deconvolution (MED) technique for 
fault detection, fault classification and fault location on transmission line. This comparison is depends on the fault detection time and fault distance on overhead transmission line which is used to analyze the test result. Both these transmission line protection techniques are tested on the MATLAB/SIMULINK environment and it detect the fault correctly and classify all possible eleven types of fault and the fault location is based on local fault information for source terminal end to remote terminal end and the test result are illustrated as following tables.

\section{A. Fault Detection and Classification}

TABLE.4. RESULT COMPARISON OF FAULT DETECTION, CLASSIFICATION FOR WT AND AR $\&$ MED TECHNIQUE

\begin{tabular}{|c|c|c|c|}
\hline \multirow{12}{*}{$\begin{array}{l}\quad \text { De } \\
\text { lay } \\
\text { Time } \\
\text { (sec) }\end{array}$} & $\begin{array}{r}\text { Type } \\
\text { of fault }\end{array}$ & $\begin{array}{c}\text { Wavelet } \\
\text { Transform } \\
\text { Method (sec) }\end{array}$ & $\begin{array}{c}\text { AR and MED } \\
\text { Method } \\
(\mathrm{sec})\end{array}$ \\
\hline & $\mathrm{AG}$ & 2.7545 & 8.4566 \\
\hline & $\mathrm{BG}$ & 1.3449 & 9.5914 \\
\hline & $\mathrm{CG}$ & 1.3729 & 9.5814 \\
\hline & $\mathrm{AB}$ & 1.3396 & 8.0158 \\
\hline & $\mathrm{BC}$ & 1.3360 & 9.3152 \\
\hline & $\mathrm{AC}$ & 1.3409 & 11.1394 \\
\hline & $\mathrm{ABG}$ & 1.4270 & 8.1487 \\
\hline & $\mathrm{BCG}$ & 1.3531 & 9.4667 \\
\hline & $\mathrm{ACG}$ & 1.3360 & 11.1288 \\
\hline & $\mathrm{ABC}$ & 1.3266 & 8.9361 \\
\hline & $\begin{array}{l}\mathrm{ABC} \\
\mathrm{G}\end{array}$ & 1.3240 & 8.7305 \\
\hline
\end{tabular}

\section{B. Fault Location}

TABLE.5. RESULT COMPARISON OF FAULT LOCATION ON BUS 1 WITH RESPECT TO BUS 2 AS REMOTE TERMINAL FOR WT AND AR \& MED TECHNIQUE

\begin{tabular}{|c|c|c|c|}
\hline No & $\begin{array}{l}\text { Type of } \\
\text { Fault }\end{array}$ & $\begin{array}{l}\text { Wavelet } \\
\text { Transform Method } \\
\text { (Distance km) }\end{array}$ & $\begin{array}{l}\text { AR and MED } \\
\text { Method } \\
\text { (Distance } \mathrm{km} \text { ) }\end{array}$ \\
\hline 1 & $\mathrm{AG}$ & $5.796102 \mathrm{e}+001$ & $5.714771 \mathrm{e}+001$ \\
\hline 2 & $\mathrm{BG}$ & $1.261484 \mathrm{e}+002$ & $1.955159 \mathrm{e}+002$ \\
\hline 3 & $\mathrm{CG}$ & $1.253662 \mathrm{e}+002$ & $1.955159 \mathrm{e}+002$ \\
\hline 4 & $\mathrm{AB}$ & $6.209132 \mathrm{e}+001$ & $5.719602 \mathrm{e}+001$ \\
\hline 5 & $\mathrm{BC}$ & $1.009663 \mathrm{e}+002$ & $7.519201 \mathrm{e}+001$ \\
\hline 6 & $\mathrm{AC}$ & $5.871901 \mathrm{e}+001$ & $7.519201 \mathrm{e}+001$ \\
\hline 7 & $\mathrm{ABG}$ & $5.768345 \mathrm{e}+001$ & $5.714771 \mathrm{e}+001$ \\
\hline 8 & $\mathrm{BCG}$ & $1.179324 \mathrm{e}+002$ & $7.519201 \mathrm{e}+001$ \\
\hline 9 & $\mathrm{ACG}$ & $5.531259 \mathrm{e}+001$ & $7.519201 \mathrm{e}+001$ \\
\hline 10 & $\mathrm{ABC}$ & $6.209132 \mathrm{e}+001$ & $5.719201 \mathrm{e}+001$ \\
\hline 11 & $\mathrm{ABCG}$ & $6.209132 \mathrm{e}+001$ & $1.955159 \mathrm{e}+002$ \\
\hline
\end{tabular}

From the result comparison the WT based transmission line fault detection, classification and location method is achieved the better result than compared to the AR and MED technique in terms of delay time to detect the transient fault signal from the transmission line faults. The average time consumption for detecting, classifying and locating the fault from the transmission line is consider as $1.4 \mathrm{sec}$ for proposed WT method, and the average time consumption for AR and MED technique is required as $9.3 \mathrm{sec}$ for detecting, classifying and locating the fault in transmission line.

\section{CONCLUSION}

A new algorithm for fault detection, classification and location on transmission line using wavelet transform is proposed. The proposed logic is based on DWT which is used to detect the transient fault current signal and extract the high frequency detail coefficient it used to detect, classify and locate all eleven type of fault in transmission line. The DWT is used as the 'db6' as a mother wavelet. The characteristic of present of ground is different when compared to the non-faulted phase which is used to easily calculate the adaptive threshold $\mathrm{Tg}$ and classify all eleven type of fault correctly. This is achieved by using the karrenbaur transformation it does not require multiplication. The proposed algorithm is tested under MATLAB/SIMULINK environment with different fault condition and this system result is compared with the AR and MED technique. In result comparison the DWT based proposed method is achieved better result than the AR and MED technique. The proposed algorithm is considered the average fault delay time for fault detection, classification and location is required as $1.4 \mathrm{sec}$ and this algorithm is very reliable, fast and secure.

\section{FUTURE WORK}

The next part of this proposed algorithm is too combined with the neural network and fuzzy logic, for fault detection, classification and location for all eleven types of possible faults on transmission line in a power system with good accuracy, fast and reliable.

\section{REFERENCE}

1. Umar Saleem; M. Nadeem Anjum; Usman Arshad, Bilal Masood "Faults detection and diagnosis of transmission lines using wavelet transformed based technique" IEEE Jordan Conference on Applied Electrical Engineering and Computing Technologies (2017), 0.1109/AEECT.2017.8257776

2. Shilpi sahu, Dr.A.K. Sharma "Detection of fault location in transmission line using wavelet transform” Int. Journal of Engineering Research and applications, Vol.3, Issue 5, Sep-Oct 2.13,pp.149-151.

3. A.Y. Abdelaziz, M.A.L. Badr, Mustafa S. Ahmed "Fault Location estimation on transmission lines using Wavelet transform" Journal of Advance science and Engineerng Research Vol 3, No 3 September (2013) 252-268.

4. Ismail Niazy, JavadSadeh "A new single ended fault location algorithm for combined transmission line considering fault clearing transients without using line parameters" ELSEVIER - Electrical Power and Energy Systems 44 (2013) 816-823.

5. Reena Sharma, Aziz Ahmad, Shailendra Kr. Saroj "Protection of transmission lines using Discrete wavelet transform" International Journal of Innovative Technology and Exploring Engineering (IJITEE) ISSN: 2278-3075, Vol-3, Issue-1, June 2013.

6. KulkarnisakekarSumant Sudhir "Wavelet Based Fault detection \& ANN Based Fault Classification in transmission line protection scheme"International Journal of Engineering Research \& Technology (IJERT) ISSN: 2278-0181, Vol. 2Issue 5, May - 2013.

7. D.Prabhavanthi, K.Prakasam, M.Suryakalavathi, Bhumanapally. Ravindhranath Reddy "Identification and classification of faults in High Voltage Radial Ug Cables by Wavelet Transform” International Journal of Engineering Science Invention ISSN 2319-6726 Volume 2 Issue 3| March 2013\| pp.01-08

8. G.Bannu and Dr.S.Suja "Fault Location Technique for UHV Lines Using Wavelet Transform" International Journal of Electrical Engineering, ISSN 0974-2158 Volume 6, November 1 (2013), pp. 77-88.

9. Soumyadip Jana, Gaurab Dutta "Wave; et Entropy and Neural Network Based Fault Detection on A Non Radial Power System Network” IOSR Journal of Electrical and Electronics Engineering (IOSRJEEE), ISSN: 2278-1676 Volume 2, Issue 3 (Sep-Oct.2012), 26-31. 
10. Ravindra Malkar, Vaibhav Magdum, Sunil Kumar Gunda "TRANSMISSION LINE FAULT ANALYSIS USING WAVELET THEORY", International Journal of Engineering Science and Technology (IJEST), ISSN: 0975-5462 Vol. 4 No.06 June 2012.

11. Mamta Patel, R.N.Patel "Fault Detection and Classification on a Transmission Line using Wavelet Multi Resolution Analysis and Neural Network", International Journal of Computer Applications (0975-8887) Volume 47-No.22, June 2012.

12. U. Roshni \& V. Niranjan, Ch. Das Prakash \& R. Srinivas Rao "Location of Fault in Transmission Line Using Fast Fourier Transform and Discrete Wavelet Transform in Power System," Undergraduate Academic Research Journal (UARJ), ISSN : 2278 1129, Volume-1, Issue-1, 2012.

13. TejashKhodiyar, EbhaKoley, Anamika Yadav, A. S. Thoke "Protection of Six Phase Transmission Line Against Phase to Phase Faults", Proc. Of the Intl. Conf. on Advances in Computer, Electronics and Electrical Engineering, 2012, ISBN : 978-981-07-1847-3.

14. V. S. Kale, S. R. Bhidle, and P. P. Bedekar "Faulted Phase Selection Based on Wavelet Analysis of Traveling Wavaes," International Journal of Computer and Electrical Engineering, Vol. 3, No. 3, June 2011.

15. S. Sajedi, F. Khalifeh, Z. Khalifeh, T. Karimi "Application of Wavelet Transform For Identification of Fault Location on Transmission Line," Australian Journal of Basic and Applied Sciences, 5(12): 1428-1432, 2011. ISSN 1991-8178.

16. S. A. Shaaban, Prof. Takashi Hiyama "Transmission Line Faults Classification Using Wavelet Transform," Proceeding of the 14th International Middle East Power Systems Conference (MEPCON'10), Cairo University, Egypt, December 19-21, 2010, Paper Id 225.

17. Dr. Hilal AI-Nasseri "Fault Detection in Overhead Transmission Line Using the Wavelet Transform", GCC-CIGRE-2010, GCC Power 2010 Conference \& Exhibition, Doha 18-20 Oct. 2010.

18. J. Upendar, C. P. Gupta, Member, IEEE, and G. K. Singh "Discrete Wavelet transform and Granitic Algorithm based Fault Classification of Transmission system", Fifteenth National Power Systems Conference (NPSC), IIT Bombay, December 2008.

19. AtthapolNagaopitaKKul and AnantaeatKunakorn "Inter Fault Classification in Transformer Windings using Combination of Discrete Wavalet Transforms and Back-Propagation Neural Networks", International Journal of Control, Automation and Systems, Vol.4, no.3, pp.365-371, Jun

20. N. Nithiyanandam, K. Venkatesh, M. Rajesh, Transfer The Levels Of The Monitored Carbon, Nitrogen Gases From The Industries, International Journal of Recent Technology and Engineering, Volume-7 Issue-6S3 April, 2019.

21. Sivanesh Kumar, A., Brittoraj, S., Rajesh, M., Implementation of RFID with internet of things, Journal of Recent Technology and Engineering, Volume-7 Issue-6S3 April, 2019.

22. Rajesh, M., Sairam, R., Big data and health care system using mlearningJournal of Recent Technology and Engineering, Volume-7 Issue-6S3 April, 2019.

23. Rajesh, M., and J. M. Gnanasekar. "Path Observation Based Physical Routing Protocol for Wireless Ad Hoc Networks." Wireless Personal Communications 97.1 (2017): 1267-1289. 